\title{
Response of fabric insert injection overmolding pp based composites subjected to single and muti-impact
}

\author{
T. Febra, J.A.M. Ferreira, J. D. Costa, J. da Silva \\ CEMMPRE, University of Coimbra, Department of Mechanical Engineering, Portugal \\ tiago_Febra@geco-moldes.pt, http:/ / orcid.org/0000-0002-9372-5072 \\ martins.ferreira@dem.uc.pt,bttp://orcid.org/0000-0002-0295-1841 \\ jose.domingos@dem.uc.pt, bttp:// orcid.org/0000-0002-8274-3734 \\ joel.jesus@uc.pt, http:/ /orcid.org/0000-0002-7133-2331 \\ C. Capela \\ Instituto Politécnico de Leiria, ESTG, Department of Mechanical Engineering, Portugal \\ ccapela@ipleiria.pt, bttp://orcid.org/0000-0003-3334-4945
}

\begin{abstract}
This paper presents the results of a current study on the development and impact response of composite plates manufactured by injection overmolding on the two sides of a single reinforcement fibre mat. The injection polymer is a talc-filled polypropylene, nowadays used for structural purposes. Three configurations with different insert fibre mats were used: Kevlar, biaxial and multiaxial glass fibre mats. The parameters studied were the fibre mat type and the impact energy. For single impact tests, it was concluded that the highest impact energy required to achieve impactor perforation is obtained with Kevlar insert, while the highest percentage of energy recovered is achieved with biaxial glass fibre netting. Kevlar insert also allows for the maximum impact stiffness. For the multi-impact tests, the recovered energy and the dynamic stiffness show the same tendencies of the single impact tests. On low energy impacts, the effect of the insert fibre and of the previous impact are quite reduced, while for impact energies above 6J, previous impacts reduce significantly the recovered energy and the impact energy for which the perforation was achieved.
\end{abstract}

KEYwORDS. Composites; Impact response; Injection overmolding.

\section{OPEN ACCESS}

Citation: T. Febra, J.A.M. Ferreira, J. D. Costa, J. da Silva, C. Capela, Response of fabric insert injection overmolding pp based composites subjected to single and mutiimpact, Frattura ed Integrità Strutturale, 48 (2019) 242-248.

Received: 14.09 .2018

Accepted: 09.01.2019

Published: 01.04.2019

Copyright: (C) 2019 This is an open access article under the terms of the CC-BY 4.0, which permits unrestricted use, distribution, and reproduction in any medium, provided the original author and source are credited.

\section{INTRODUCTION}

7 his paper is concerned with the manufacture and performance of a single piece final product made from a fibre mat insert with polymer injected overmolding in both sides. Polymers and fibre mats have very different mechanical properties but should remain safely bonded throughout their useful life. 
Traditional overmolding is a two-stage sequential process in which a previously injected rigid polymer substrate is overmolded with a more flexible thermoplastic material. The final component is a single piece composed by two polymers with very different mechanical properties. The adhesion between the two materials is the key for a successful practice use, by which the component must be safe and the interface remain permanently bonded. Nowadays, polypropylene (PP) is a widely used material for structural purposes because of its mechanical properties, reasonable cost, easy processing and recyclability. Optimization procedures for overmolding parameters have been developed and published [1-4].

Recently, fibre reinforcement mats have been used as the substrate material for some applications where final stiffness can play important role. The overmolding process requires the merging of several characteristics to increase its functionality, including combinations of mechanical strength and touch feeling or grip ability, cushioning against vibration or impact, or esthetical factors like gloss. The rigid substrate provides the basic mechanical properties for structural purposes while the soft polymer cover adds the desired user comfort and product functionalities.

The increasing use of overmolding components can be seen in applications such as automotive interiors, medical devices, telephone keypads, toothbrushes, shaving hardware, household appliances and hand tools [5-7]. Nowadays, polypropylene (PP) is replacing traditional engineering thermoplastics for structural purposes in automotive applications, due to its mechanical properties, reasonable cost, easy processing and recyclability.

A low velocity impact event is one of the most dangerous loads on composite laminates, giving rise to different types of damages, including matrix cracking, fibre fracture, fibre-matrix debonding and delamination between different layers [8]. Internal delamination induces premature buckling of the structures with the consequent drop of compressive strength [9, $10]$ and also in less relevant of the tensile strength [11].

The response of composites subjected to single-impact loading is abundantly reported on scientific literature, also repaired composites [12, 13]. Andrew et al. [13] evaluated the residual compression after low-velocity impacts on GFRP composites repaired by Kevlar chopped short fibres/epoxy and found higher maximum impact load and lower contact time for repaired specimens relatively to the unrepaired ones.

However, scarce information can be found about the performance of composites under repeated impacts. This subject was studied by Morais et al [14], concluding that stacking sequences and laminate thickness have a major influence on the composite's response under repeated impacts.

The structural performance under repeated impacts was studied by Cholakara et al [15] on Kevlar-fibre/epoxy composites, by Mouritz et al [16] and by Hosur et al [17] on glass reinforced laminates and by Wyrick and Adams [18] on the carbon/epoxy laminates.

The parameters studied were the fibre mat type and the impact energy. The impact response was monitored in terms of the maximum load and displacement, dynamic impact modulus, absorbed and recovered energies and damage area.

In addition to the study of the influence of the aforementioned parameters regarding simple impact response, this work also aims to compare the response of the material to simple impact and multi-impact with increasing energies.

\begin{tabular}{cccccc}
\hline Reference & Matrix & Insert & $\begin{array}{c}\text { Mould } \\
\text { Temp. }\left({ }^{\circ} \mathrm{C}\right)\end{array}$ & $\begin{array}{c}\text { Processing } \\
\text { Temp. }\left({ }^{\circ} \mathrm{C}\right)\end{array}$ & $\begin{array}{c}\text { Injection pressure } \\
\text { (Bar) }\end{array}$ \\
MGFm & Talc-filled PP & Multiaxial glass fiber mesh & 22 & 220 & 41 \\
BGFn & Talc-filled PP & Biaxial glass fiber netting & 22 & 220 & 41 \\
Km & Talc-filled PP & Kevlar mat & 22 & 220 & 41 \\
\hline
\end{tabular}

Table 1: Formulation and manufacture parameters of the composites.

\section{MATERIALS AND TESTING}

he present work studied impact response using square $100 \times 100 \mathrm{~mm} 2$ and $3 \mathrm{~mm}$ nominal thickness specimens. The overmolding matrix was polypropylene (PP) filled by $20 \%$ in weight of talk, Hostacom TRC 352N Titan supplied by Yonde Basel. Three configurations with different insert fibre mats were manufactured, as is summarized in Table 1. In turn, the glass fibre inserts used were fiberglass multiaxial mesh fabric and biaxial fiberglass reinforcing mesh, supplied by HUESKER. The third insert was an Aramid Kevlar 49 mesh, supplied by Toray. The injection moulding process was carried out using a Sandreto 200 Ton machine, using the parameters indicated in Table 1 . Fig. 1 shows the insert fibre mat placed in the mould. 
Low-velocity impact tests were performed using a drop weight-testing machine Instron-Ceast 9340. An impactor with a diameter of $10 \mathrm{~mm}$ and mass of $3.4 \mathrm{~kg}$ was also used. The tests were performed with the impactor stroke at the centre of centrally supporting the $100 \times 100 \mathrm{~mm}$ specimens.

Two types of tests were carried out: single impact tests for different impact energies and multi-impacts tests in which the specimens were subjected to successive impacts with increasing energy. For each condition, two/three specimens were tested at room temperature.

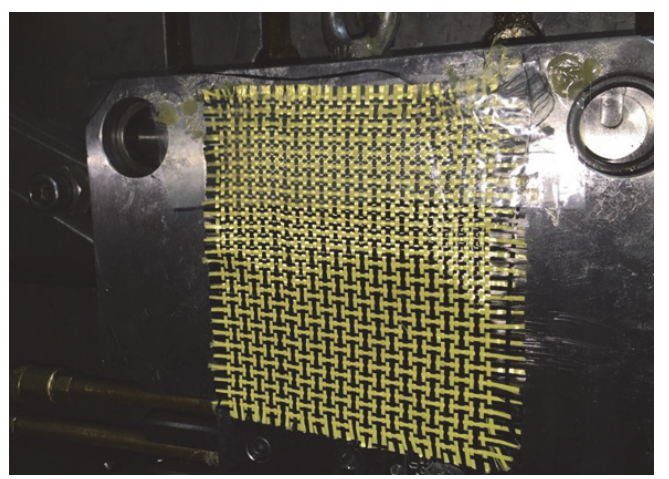

Figure 1: View of the insert fibre mat placed in mould.

\section{RESULTS AND DISCUSSION}

\section{Single impact tests}

$\mathrm{F}$ ig. 2a) shows typical energy versus time curves, while Fig. 2b) presents the dynamic load against the displacement, both for the three different insert fibre mats samples. All these tests were performed with an impact energy of $6 \mathrm{~J}$. Fig. 2a) also shows that maximum energy was achieved quickly in the Kevlar mat composite, due to its higher dynamic stiffness, as demonstrated in Fig. 3b). For this type of impact energy multiaxial glass fibre mesh has the lower recovered energy, which is quite similar for the other two insert mats.
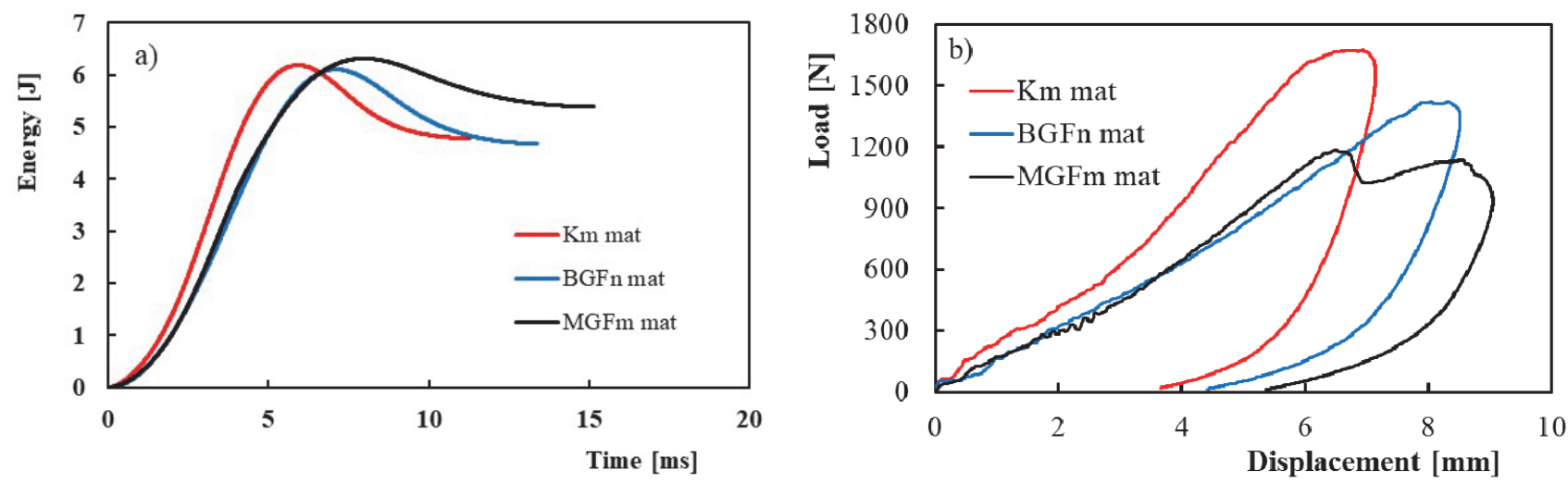

Figure 2: Influence of the insert material on the impact response for $6 \mathrm{~J}$ impact energy: a) Energy versus time; b) Load versus displacement.

Fig. 3a) presents the average values of three tests for each condition of the recovered energy versus impact energy, showing that biaxial glass fiber netting insert promotes the highest values of recovered energy, contrary to what happens with multiaxial glass fiber mesh insert which was observed as having a lower perforation energy.

Fig. $3 \mathrm{~b}$ ) presents the dynamic impact stiffness (calculated as the ratio between the maximum load and the displacement at maximum load) against the displacement, showing a slow decrease for the three insert fibers only for impact energies higher than $10 \mathrm{~J}$. Kevlar composites exhibit dynamic stiffness more than $25 \%$ higher than both glass fiber composites. 

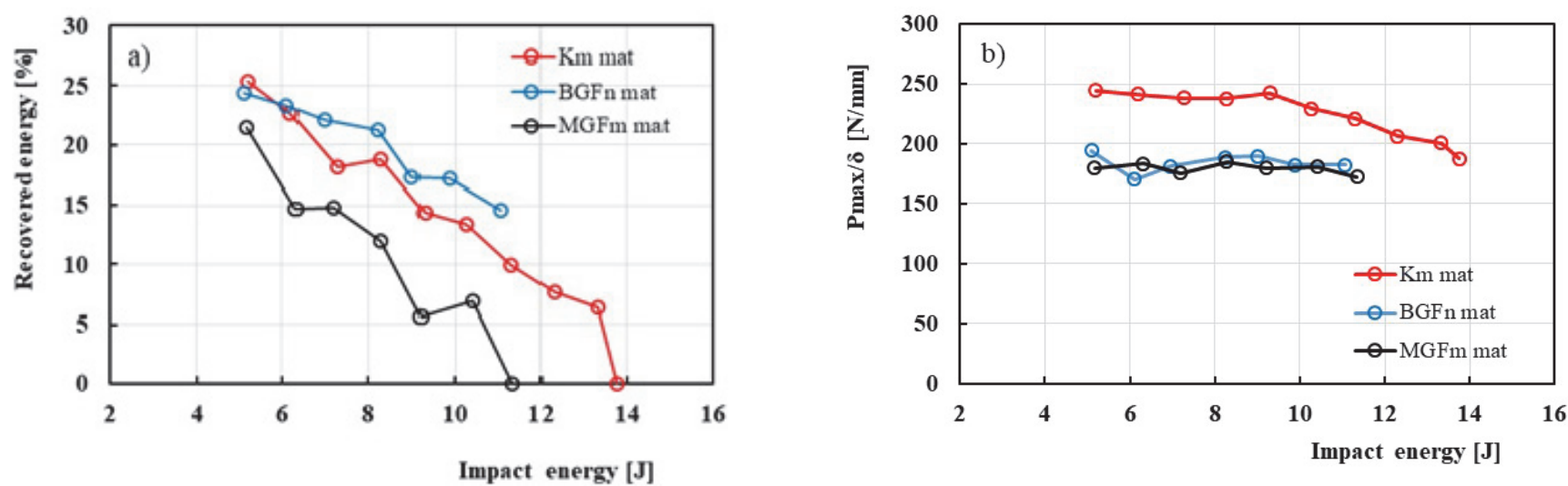

Figure 3: Influence of impact energy on response parameters: a) Recovered energy versus impact energy; b) Dynamic modulus versus impact energy.

Figs. 4a) and 4b) show exemplary photos of the damage zones on a talc filled PP with multiaxial glass fibre mesh insert (MGFm) sample tested for impact energy of 6J in impact side and back side, respectively. As well reported in literature for fiber-reinforced composites [19], higher damage occurred in the backside in which a long failure crack is observed, while in the impact side only a regular plastic deformation caused by impactor occurs.
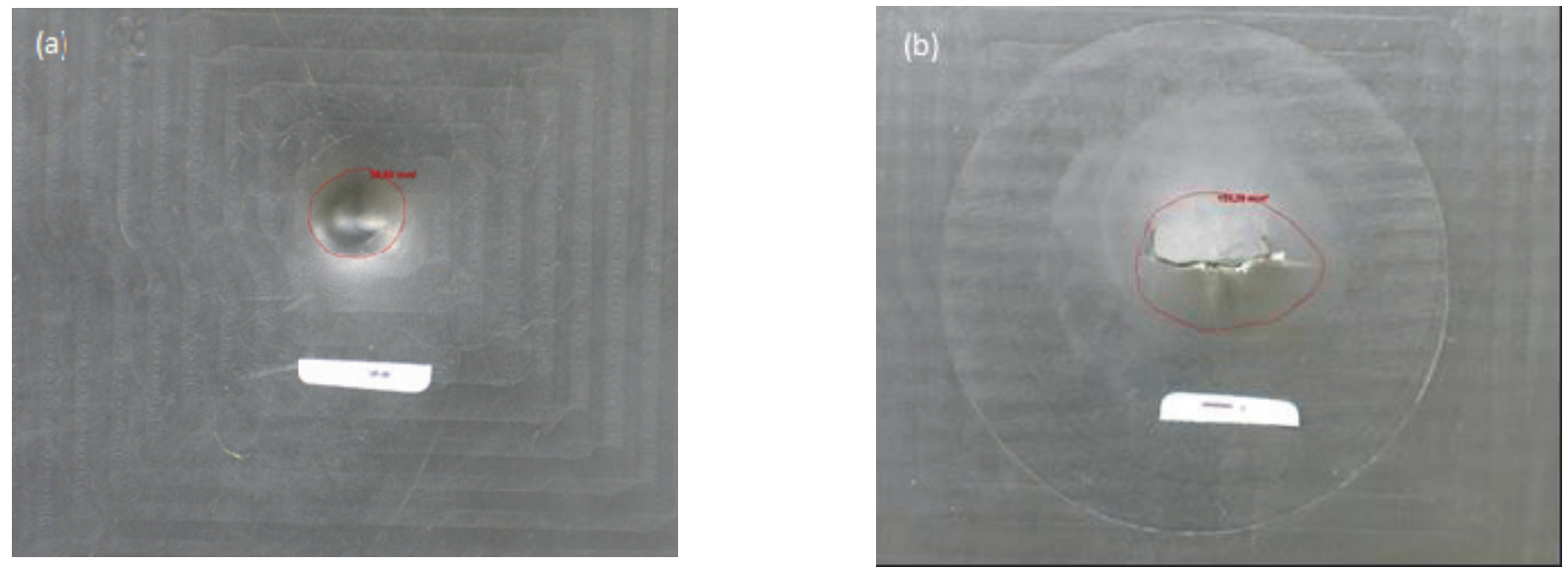

Figure 4: Exemplary photos of the damage on a MGFm sample tested for impact energy of 6J: a) Impact side; b) Back side.

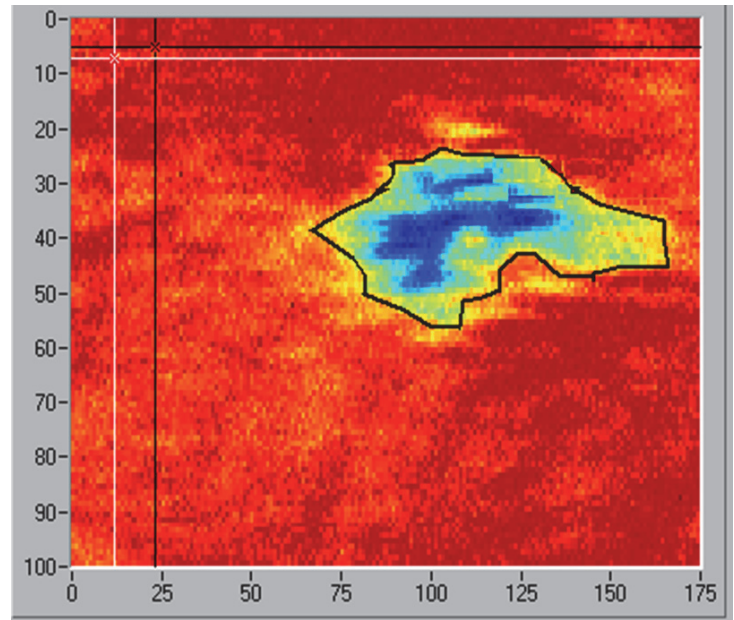

(a)

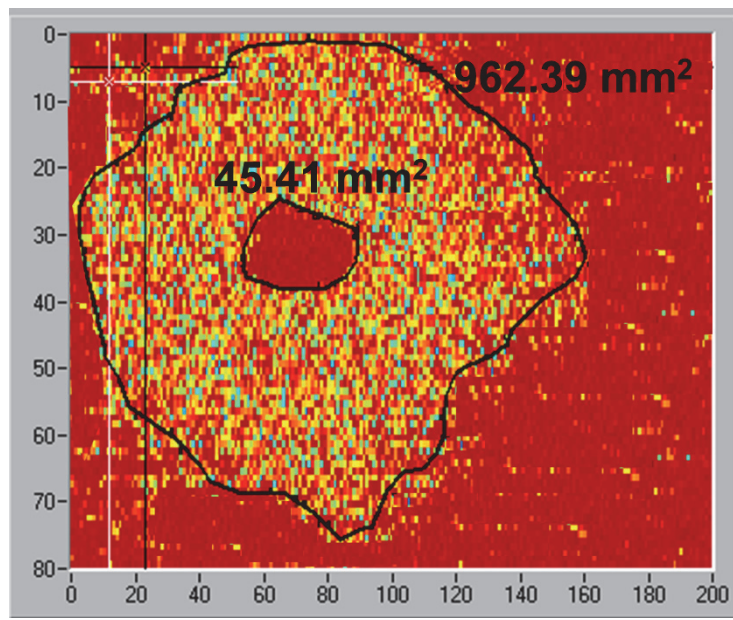

(b)

Figure 5: Exemplary Cscan images of damaged zones for impact energy of 5J: a) BGFn mat; b) Km mat. 
Some samples were inspected by C-Scan technique, supplied by Physical Acoustics Cooperation, in order to analyze the damaged zone. Figure 5 shows the typical and representative images of the BGFn mat and Km mat samples, impacted by 5J. It is possible to observe that, in spite of the higher damaged area of the Km mat sample, the C-Scan image for BGFn mat insert suggests a much more intense damage. These observations are in accordance with the lower dynamic stiffness obtained in Fig. 3b) for the BGFn mat inserts. Similarly to what happens in sandwich composites, three types of failure can be observed: rupture of the superficial polymer layers, delamination of the interface and in extreme conditions, rupture of the fibers [20].

\section{Multi-impact tests}

The results of the multi-impact tests (in which the same specimen was subjected to successive impacts with impact energy increasing successively 1J for each test) are summarized in Figures 6 and 7, in terms of the recovered energy (in percentage of the impact energy) and the dynamic stiffness, respectively. Fig. 6 shows the same tendencies of the single impact tests presented in Fig. 3a), indicating that biaxial glass fibre netting inserts promote the highest values of recovered energy. However, the multiaxial glass fibre mesh insert shows the lower recovered energy and perforation energy. Recovered energy decreases parabolic until failure, according with F. Cucinotta et al. [20]. Also, as in the single impact tests presented in Fig. 3b) Kevlar inserts exhibit the highest dynamic stiffness, in contrast to glass fibre inserts (Fig. 7). In any case, a significant difference was observed on the dynamic stiffness values for the multi-impacted specimens in comparison with the single impacted tests, decreasing significantly after the peaking for an intermediate impact energy. This fact is caused by the accumulated damage occurred at the intermediate impact energy.

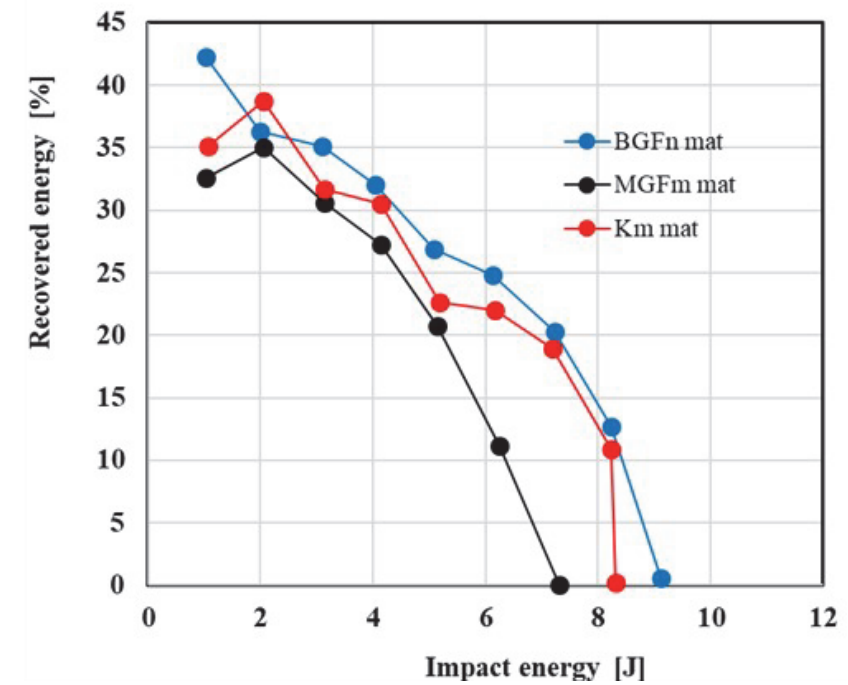

Figure 6: Recovered energy after multi-impact tests.

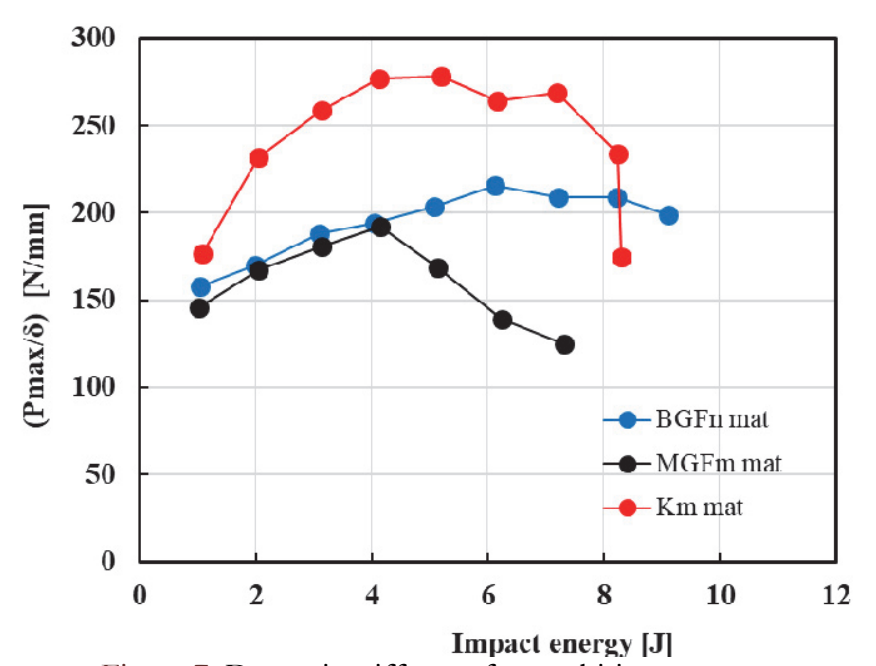

Figure 7: Dynamic stiffness after multi-impact tests.

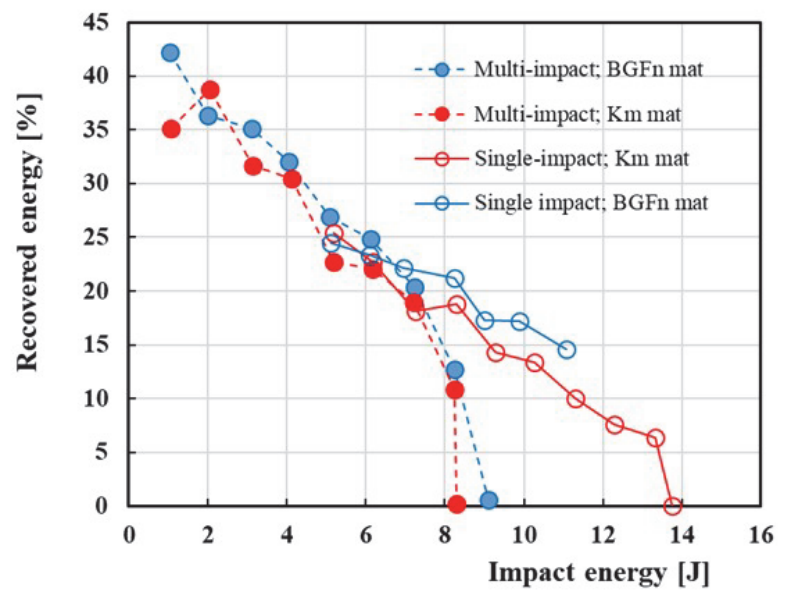

Figure 8: Comparison of the recovered energy for multi-impact and single impact tests. 
Fig. 8 compares the results of the recovered energy obtained for the multi-impacts and the single impact tests. The results indicate that for low energy the effect of the insert fibre and of the previous impact is quite reduced. However, for impact energies above 6J, previous impacts significantly reduce the recovered energy and the impact energy for which the perforation was achieved. The BGFn mat insert promotes a slightly improved impact response for both series of tests.

\section{CONCLUSIONS}

$\mathrm{T}$ he present work studied the effect of the fiber type on the impact response of insert injection overmolding talc filled PP composites subjected to single impact and the multi-impacts tests, for which successive impacts with increasing energy were applied. The main conclusions that can be drawn were as follows:

- For single impact tests, the highest impact energy required to achieve impactor perforation is obtained with Kevlar insert while the highest percentage of energy recovered is achieved with biaxial glass fiber netting. The maximum impact stiffness was obtained with Kevlar insert, with both glass fibre inserts achieving similar results. The maximum post-impact load was also obtained with Kevlar insert, while the minimum for the multiaxial glass fibre mesh;

- For the multi-impact tests, the recovered energy and the dynamic stiffness show the same tendencies of the single impact tests. However, a significant difference was observed on the dynamic stiffness values for the multi-impacted specimens which decrease significantly after the peaking for an intermediate impact energy;

- The comparison of the recovered energy obtained for the multi-impact and single impact tests show that for low energy the effect of the insert fibre and of the previous impact is quite reduced, while for impact energies above $6 \mathrm{~J}$ previous impacts reduce significantly the recovered energy and the impact energy for which the perforation was achieved.

\section{ACKNOWLEDGMENTS}

7 he authors would like to acknowledge GECO-Moldes, Leiria, Portugal, for the supply of the samples and the sponsoring of this research by FEDER funds through the program COMPETE - Programa Operacional Factores de Competitividade - and by national funds through FCT - Fundação para a Ciência e a Tecnologia -, under the project UID/EMS/00285/2013.

\section{REFERENCES}

[1] Carella, A.R., Alonso, C., Merino, J.C., Pastor, J.M. (2002). Sequential injection of thermo-plastic polymers. Analysis of processing parameters for optimal bonding conditions, Polym Eng Sci, 42, pp. 2172-2181.

[2] Schellekens, M., Twene, D., Vander Waals, A. (2011). Block copolymers for waterborne coatings-a novel ecofriendly approach for improved coating adhesion to untreated polypropylene based plastics. Prog Org Coat, 72, pp. 138-143. DOI: 10.1016/j.porgcoat.2011.03.007

[3] Dondero, M., Pastor, J.M., Carella, J.M., Perez, C.J. (2009). Adhesion control for injection overmolding of polypropylene with elastomeric ethylene copolymers. Polym Eng Sci, 49, pp. 1 886-1893.

[4] Nguyen, S., Perez, C.J., Desimone, M., Pastor, J.M., (2013). Overmolding of elastomeric propylene copolymers on polypropylene. Effects of block and random microstructures. International Journal of Adhesion \& Adhesives, 46, pp 44-55. DOI: 10.1016/j.ijadhadh.2013.05.016

[5] Huang, D.Y., Chen, R.S. (1999). Bonding strength at solid-melt interface for polystyrene in a sequential two-staged injection molding process, Polym Eng Sci, 39, pp. 2159-2171.

[6] Weng, D., Andries, J., Morin, P., Saunders, K., Politis, J. (2000). Fundamentals and material development for thermoplastic elastomer(TPE) overmolding. J Injection Molding Technol, 4, pp.22-28.

[7] Richardson, M.O.W., Wisheart, M.J. (1996). Review of low-velocity impact properties of composite materials. Compos Part A-Appl S, 27, pp. 1123-1131. DOI: 10.1016/1359-835X(96)00074-7.

[8] Lankford, J. (1997). Shear versus Dilatational Damage Mechanisms in the Compressive Failure of Fibre Reinforced Composites. Compos Part A-Appl S, 28, pp. 215-222. DOI: 10.1016/S1359-835X(96)00110-8.

[9] Lee, S.H., Yerramalli, C.S., Waas, A.M. (2000). Compressive Splitting Response of Glass-fiber Reinforced Unidirectional Composites. Compos Sci Technol, 60, pp. 2957-2966. DOI: 10.1016/S0266-3538(00)00159-7. 
[10] Reis, P.N.B., Ferreira, J.A.M., Antunes, F.V., Richardson, M.O.W. (2009). Effect of Interlayer Dalamination on Mechanical Behavior of Carbon/Epoxy Laminates. J Compos Mater, 43, pp. 2609-2621.

DOI: $10.1177 / 0021998309344649$.

[11] Balc, O., Çoban, O., Bora, M.Ö., Akagündüz, E., Yalçin, E.B. (2017). Experimental investigation of single and repeated impacts for repaired honeycomb sandwich structures. Mat Sci Eng A-Struct, 682, pp. 23-30. DOI: 10.1016/j.msea.2016.11.030.

[12] Andrew, J.J., Arumugam, V., Saravanakumar, K., Dhakal „H.N., Santuli ,C. (2015). Compression after impact strength of repaired GFRP composite laminates under repeated impact loading. Compos Struct, 133, pp. 911-920.

[13] de Morais, W.A., Monteiro, S.N., d'Almeida, J.R.M. (2005). Effect of the Laminate Thickness on the Composite Strength to Repeated Low Energy Impacts. Compos Struct, 70, pp. 223-228. DOI: $10.1016 /$ j.compstruct.2004.08.024.

[14] Cholakara, M.T., Jang, B.Z., Wang, C.Z. (1989). Deformation and Failure Mechanisms in 3D Composites. In Proc. 34th Int. SAMPE Conference, May 8-11, pp. 2153-2160.

[15] Mouritz, A.P., Gallagher, J., Goodwin, A.A. (1997). Flexural Strength and Interlaminar Shear Strength of Stitched GRP Laminates Following Repeated Impacts. Compos Sci Technol, 57, pp. 509-522. DOI: 10.1016/S0266-3538(96)00164-9.

[16] Hosur, M.V., Karim, M.R., Jeelani, S. (2003). Experimental Investigations on the Response of Stitched/unstitched Woven S2-glass/SC15 Epoxy Composites Under Single and Repeated Low Velocity Impact Loading. Compos Struct, 61, pp. 89-102. DOI: 10.1016/S0263-8223(03)00032-1.

[17] Wyrick, D.A., Adams, D.F. (1988). Damage Sustained by a Carbon/epoxy Composite Material Subjected to Repeated Impact. Composites, 19, pp. 19-26. DOI: 10.1016/0010-4361(88)90540-X.

[18] Reis, P.N.B., Ferreira, J.A.M., Zhang, Z.Y., Benameur, T., Richardson, M.O.W. (2013). Impact response of Kevlar composites with nanoclay enhanced epoxy matrix. Composites: Part B 46, pp. 7-14. DOI: $10.1016 /$ j.compositesb.2012.10.028.

[19] Cucinotta, F., Paoli, A., Risitano G. and Sfravara F.(2018). Proceedings of the Institution of Mechanical Engineers Part M: Journal of Engineering for the Maritime Environment, 232 ( 2), pp. 234-244.

DOI: 10.1 177/1475090217720619.

\section{NOMENCLATURE}

BGFn - Biaxial glass fiber netting;

GFRP - Glass fibre reinforced polymers;

Km - Kevlar mat;

MGFm - Multiaxial glass fiber mesh. 